\title{
Cardiovascular events and all-cause mortality in a cohort of 57,946 patients with type 2 diabetes: associations with renal function and cardiovascular risk factors
}

\author{
Lucia Cea Soriano1, Saga Johansson², Bergur Stefansson² and Luis A García Rodríguez ${ }^{1 *}$
}

\begin{abstract}
Background: Diabetes and chronic kidney disease (CKD) are independent predictors of death and cardiovascular events and their concomitant prevalence has increased in recent years. The aim of this study was to characterize the effect of the estimated glomerular filtration rate (eGFR) and other factors on the risk of death and cardiovascular events in patients with type 2 diabetes.

Methods: A cohort of 57,946 patients with type 2 diabetes who were aged 20-89 years in 2000-2005 was identified from The Health Improvement Network, a UK primary care database. Incidence rates of death, myocardial infarction $(\mathrm{MI})$, and ischemic stroke or transient ischemic attack (IS/TIA) were calculated overall and by eGFR category at baseline. eGFR was calculated using the Modification of Diet in Renal Disease (MDRD) study equation. Death, MI and IS/TIA cases were detected using an automatic computer search and IS/TIA cases were further ascertained by manual review of medical records. Hazard ratios (HRs) and their corresponding 95\% confidence intervals (Cls) for death, MI, and IS/TIA associated with eGFR category and other factors were estimated using Cox regression models adjusted for potential confounders.
\end{abstract}

Results: Overall incidence rates of death (mean follow-up time of 6.76 years), MI (6.64 years) and IS/TIA (6.56 years) were 43.65, 9.26 and 10.39 cases per 1000 person-years, respectively. A low eGFR (15-29 mL/min) was associated with an increased risk of death (HR: 2.79; 95\% Cl: 2.57-3.03), MI (HR: 2.33; 95\% Cl: 1.89-2.87) and IS/TIA (HR: 1.77; 95\% Cl: 1.43-2.18) relative to eGFR $\geq 60 \mathrm{~mL} / \mathrm{min}$. Other predictors of death, $\mathrm{MI}$ and IS/TIA included age, longer duration of diabetes, poor control of diabetes, hyperlipidemia, smoking and a history of cardiovascular events.

Conclusions: In patients with type 2 diabetes, management of cardiovascular risk factors and careful monitoring of eGFR may represent opportunities to reduce the risks of death, MI and IS/TIA.

Keywords: Chronic kidney disease, Estimated glomerular filtration rate, Ischemic stroke, Mortality, Myocardial infarction, Type 2 diabetes

\section{Background}

Diabetes and chronic kidney disease (CKD) are independent predictors of death and cardiovascular events [1-3]. The prevalence of CKD in individuals with diabetes has increased in recent years and studies have estimated that about $25-30 \%$ of patients with type 2 diabetes have CKD

\footnotetext{
* Correspondence: lagarcia@ceife.es

${ }^{1}$ Spanish Centre for Pharmacoepidemiologic Research (CEIFE), Almirante 28-2, E 28004 Madrid, Spain

Full list of author information is available at the end of the article
}

stages $3-5$ in the UK [4,5]. Additionally, type 2 diabetes is the most common reason for renal replacement therapy in the Western world [6].

The potential association between impaired renal function (as measured by the estimated glomerular filtration rate $[\mathrm{eGFR}]$ ) and all-cause mortality and/or incidence of cardiovascular events has been thoroughly studied in the general population [1,7-11], in patients with cardiovascular diseases [12-16] and in those with impaired renal function $[17,18]$. Although the association between decreased 
renal function and death in individuals with type 2 diabetes has been studied to some extent [19-24], data on cardiovascular mortality and morbidity remain scarce in this patient population [19,20,24-28].

The aim of this study was to determine the incidences of death, myocardial infarction (MI), and ischemic stroke or transient ischemic attack (IS/TIA) in a population of individuals with prevalent type 2 diabetes, overall and according to eGFR calculated from baseline measurement of creatinine. Risks of death, MI and IS/TIA adjusted for potential confounders (including cardiovascular risk factors) and associated with eGFR baseline measurement was also estimated. Other predictors of death and cardiovascular outcomes were also identified overall and for each CKD stage.

\section{Methods}

\section{Data source}

A retrospective cohort study was performed using data from The Health Improvement Network (THIN), a computerized primary care database containing anonymized records for individuals currently registered with participating primary care practices in the UK. THIN is age, sex and geographically representative of the UK population [29] and has been extensively validated for epidemiological studies [30,31]. Anonymized data on patients are systematically recorded by participating primary care physicians (PCPs) as part of their routine patient care and regularly delivered to THIN for use in research projects. The computerized information includes demographics, details of PCP visits, diagnoses, referrals to specialists and hospital admissions, and a free-text section. Participating practices are required to record prescriptions and new courses of therapy. THIN also provides a standardized system for the reliable and comprehensive recording of additional health data such as results of laboratory tests (including serum creatinine concentration, when appropriate). The Read classification is used to code specific diagnoses [32], and a drug dictionary based on data from the Multilex classification is used to record prescriptions [33]. The collection of data in THIN database was approved by a Multicentre Research Ethics Committee in the UK (MREC reference number: 08/H0305/49).

\section{Study design}

A cohort of patients with diagnosed type 2 diabetes who were aged 20-89 years between January 1, 2000 and December 31, 2005 was identified from THIN $(\mathrm{n}=64,755)$. The wide age range was chosen to include the general adult population with prevalent type 2 diabetes. Eligible individuals were required to be registered for at least 3 years with their PCP, to have had at least one visit recorded in the past 3 years, and to have a recorded prescription history of 3 years or more. Patients were included in the study cohort if they had at least one creatinine measurement of 10$250 \mu \mathrm{mol} / \mathrm{L}$ recorded between 1 January 2000 and 31 December 2005. Patients with a record of hemodialysis $(n=109)$ or renal transplant $(n=60)$ before their start date were excluded, and patients with a recorded incidence of hemodialysis or renal transplant during follow-up were censored from the analysis ( $\mathrm{n}=108$ for hemodialysis and $\mathrm{n}=5$ for renal transplant).

Among all individuals with type 2 diabetes meeting these criteria $(n=57,957), 56,693(97.8 \%)$ had a first recorded creatinine measurement of 10 $250 \mu \mathrm{mol} / \mathrm{L}$. The date of this first recorded creatinine measurement was defined as their start date. The remaining 1264 individuals $(2.2 \%)$ had a first creatinine measurement $<10 \mu \mathrm{mol} / \mathrm{L}(\mathrm{n}=1161)$ or $>$ $250 \mu \mathrm{mol} / \mathrm{L}(\mathrm{n}=103)$, and a subsequent measurement within the range $10-250 \mu \mathrm{mol} / \mathrm{L}$. The date of their first serum creatinine measurement between 10 and $250 \mu \mathrm{mol} / \mathrm{L}$ was defined as their start date. The mean and median times from their first recorded measurement to their start date were 341 days and 202 days, respectively. All patients were followed up from their start date to the first occurrence of either of the following endpoints in three different analyses based on the studied outcome: outcome of interest (death, MI or IS/TIA), reaching the age of 90 years, or end of the study period (December 31, 2010). It should be noted that 11 patients were excluded from the final cohort (seven individuals who had died at start date, and four who had no visits during followup), resulting in a final cohort of 57,946 patients.

\section{Ascertainment and duration of type 2 diabetes}

Type 2 diabetes diagnosis was based on the Read classification codes assigned by the PCP or use of hypoglycemic drugs or insulin. For the majority of cases, the type of diabetes was specifically reported by the physician. If the physician used an unspecific diagnostic code (e.g., diabetes mellitus), we reviewed the patient's medical record back to one year before the diagnosis including any referral letters and physicians' free-text comments to assign the type of diabetes. If the age of onset was $\leq 35$ years and the patient had one or more prescriptions for insulin and less than one year of oral hypoglycemic treatment, the case was classified as type 1 diabetes. Conversely, if the age of onset was $\geq 50$ years and the patient used oral hypoglycemic treatment for at least 1 year, the case was classified as type 2 diabetes. A previous THIN study with a similar diabetes ascertainment algorithm estimated a diabetes prevalence that closely matched the prevalence in the 
Table 1 Baseline characteristics, overall and according to estimated glomerular filtration rate category

\begin{tabular}{|c|c|c|c|c|c|c|c|c|c|c|}
\hline & \multirow{2}{*}{\multicolumn{2}{|c|}{ Overall $(\mathrm{N}=57,946)$}} & \multicolumn{8}{|c|}{ eGFR category (mL/min) } \\
\hline & & & \multicolumn{2}{|c|}{$15-29(n=972)$} & \multicolumn{2}{|c|}{$30-44(n=4326)$} & \multicolumn{2}{|c|}{$45-59(n=12,614)$} & \multicolumn{2}{|c|}{$\geq 60(n=40,034)$} \\
\hline & Number & $\%$ & Number & $\%$ & Number & $\%$ & Number & $\%$ & Number & $\%$ \\
\hline \multicolumn{11}{|l|}{ Sex } \\
\hline Men & 32,117 & 55.4 & 315 & 32.4 & 1654 & 38.2 & 5434 & 43.1 & 24,714 & 61.7 \\
\hline Women & 25,829 & 44.6 & 657 & 67.6 & 2672 & 61.8 & 7180 & 56.9 & 15,320 & 38.3 \\
\hline \multicolumn{11}{|c|}{ Age at start date (years) } \\
\hline 20-39 & 1269 & 2.2 & 0 & 0.0 & 3 & 0.1 & 30 & 0.2 & 1236 & 3.1 \\
\hline $40-49$ & 4454 & 7.7 & 8 & 0.8 & 27 & 0.6 & 187 & 1.5 & 4232 & 10.6 \\
\hline $50-59$ & 10,729 & 18.5 & 37 & 3.8 & 175 & 4.0 & 1067 & 8.5 & 9450 & 23.6 \\
\hline $60-69$ & 17,889 & 30.9 & 196 & 20.2 & 883 & 20.4 & 3623 & 28.7 & 13,187 & 32.9 \\
\hline $70-79$ & 16,933 & 29.2 & 378 & 38.9 & 1882 & 43.5 & 5303 & 42.0 & 9370 & 23.4 \\
\hline $80-89$ & 6672 & 11.5 & 353 & 36.3 & 1356 & 31.3 & 2404 & 19.1 & 2559 & 6.4 \\
\hline \multicolumn{11}{|l|}{ Smoking status } \\
\hline Non-smoker & 30,175 & 52.1 & 561 & 57.7 & 2441 & 56.4 & 7028 & 55.7 & 20,145 & 50.3 \\
\hline Current & 10,128 & 17.5 & 104 & 10.7 & 533 & 12.3 & 1671 & 13.2 & 7820 & 19.5 \\
\hline Former & 15,011 & 25.9 & 240 & 24.7 & 1105 & 25.5 & 3367 & 26.7 & 10,299 & 25.7 \\
\hline Unknown & 2632 & 4.5 & 67 & 6.9 & 247 & 5.7 & 548 & 4.3 & 1770 & 4.4 \\
\hline \multicolumn{11}{|l|}{ BMI $\left(\mathrm{kg} / \mathrm{m}^{2}\right)$} \\
\hline $15-19$ & 915 & 1.6 & 18 & 1.9 & 84 & 1.9 & 234 & 1.9 & 579 & 1.4 \\
\hline $20-24$ & 9546 & 16.5 & 174 & 17.9 & 818 & 18.9 & 2223 & 17.6 & 6331 & 15.8 \\
\hline $25-29$ & 21,011 & 36.3 & 297 & 30.6 & 1521 & 35.2 & 4757 & 37.7 & 14,436 & 36.1 \\
\hline$\geq 30$ & 22,959 & 39.6 & 362 & 37.2 & 1487 & 34.4 & 4529 & 35.9 & 16,581 & 41.4 \\
\hline Unknown & 3515 & 6.1 & 121 & 12.4 & 416 & 9.6 & 871 & 6.9 & 2,107 & 5.3 \\
\hline \multicolumn{11}{|l|}{ Number of drugs } \\
\hline$\leq 1$ & 15,007 & 25.9 & 107 & 11.0 & 626 & 14.5 & 2708 & 21.5 & 11,566 & 28.9 \\
\hline $2-4$ & 20,458 & 35.3 & 224 & 23.0 & 1185 & 27.4 & 4121 & 32.7 & 14,928 & 37.3 \\
\hline $5-9$ & 18,680 & 32.2 & 461 & 47.4 & 1920 & 44.4 & 4748 & 37.6 & 11,551 & 28.9 \\
\hline $10-14$ & 3335 & 5.8 & 158 & 16.3 & 513 & 11.9 & 906 & 7.2 & 1758 & 4.4 \\
\hline$\geq 15$ & 466 & 0.8 & 22 & 2.3 & 82 & 1.9 & 131 & 1.0 & 231 & 0.6 \\
\hline
\end{tabular}

Duration of diabetes (years)

$\begin{array}{lllllllllll}<1 & 2848 & 4.9 & 26 & 2.7 & 138 & 3.2 & 557 & 4.4 & 2127 & 5.3 \\ 1-4 & 23,201 & 40.0 & 208 & 21.4 & 1311 & 30.3 & 4545 & 36.0 & 17,137 & 42.8 \\ 5-9 & 17,123 & 29.5 & 298 & 30.7 & 1271 & 29.4 & 3786 & 30.0 & 11,768 & 29.4 \\ 10-14 & 8503 & 14.7 & 184 & 18.9 & 824 & 19.0 & 2095 & 16.6 & 5400 & 13.5 \\ \geq 15 & 6271 & 10.8 & 256 & 26.3 & 782 & 18.1 & 1631 & 12.9 & 3602 & 9.0 \\ \mathrm{HBA}_{1 \mathrm{C}}(\%) & & & & & & & & & & \\ <7.00 & 19,382 & 33.4 & 272 & 28.0 & 1463 & 33.8 & 4480 & 35.5 & 13,167 & 32.9 \\ 7.00-7.99 & 12,823 & 22.1 & 203 & 20.9 & 964 & 22.3 & 2922 & 23.2 & 8734 & 21.8 \\ 8.00-8.99 & 7221 & 12.5 & 111 & 11.4 & 480 & 11.1 & 1565 & 12.4 & 5065 & 12.7 \\ 9.00-9.99 & 4634 & 8.0 & 66 & 6.8 & 302 & 7.0 & 877 & 7.0 & 3389 & 8.5 \\ 10.00-10.99 & 2497 & 4.3 & 44 & 4.5 & 142 & 3.3 & 433 & 3.4 & 1878 & 4.7 \\ \geq 11 & 2301 & 4.0 & 43 & 4.4 & 134 & 3.1 & 409 & 3.2 & 1715 & 4.3 \\ \text { Missing } & 9088 & 15.7 & 233 & 24.0 & 841 & 19.4 & 1928 & 15.3 & 6086 & 15.2 \\ \text { PCP visits } & & & & & & & & & & \end{array}$

PCP visits 
Table 1 Baseline characteristics, overall and according to estimated glomerular filtration rate category (Continued)

\begin{tabular}{|c|c|c|c|c|c|c|c|c|c|c|}
\hline $0-4$ & 8018 & 13.8 & 87 & 9.0 & 471 & 10.9 & 1508 & 12.0 & 5952 & 14.9 \\
\hline $5-9$ & 17,371 & 30.0 & 229 & 23.6 & 1120 & 25.9 & 3640 & 28.9 & 12,382 & 30.9 \\
\hline $10-19$ & 23,024 & 39.7 & 355 & 36.5 & 1717 & 39.7 & 5228 & 41.4 & 15,724 & 39.3 \\
\hline$\geq 20$ & 9533 & 16.5 & 301 & 31.0 & 1018 & 23.5 & 2238 & 17.7 & 5976 & 14.9 \\
\hline \multicolumn{11}{|l|}{ Referrals } \\
\hline $0-4$ & 50,987 & 88.0 & 750 & 77.2 & 3634 & 84.0 & 10,976 & 87.0 & 35,627 & 89.0 \\
\hline $5-9$ & 5525 & 9.5 & 162 & 16.7 & 513 & 11.9 & 1287 & 10.2 & 3563 & 8.9 \\
\hline $10-19$ & 1315 & 2.3 & 55 & 5.7 & 162 & 3.7 & 325 & 2.6 & 773 & 1.9 \\
\hline$\geq 20$ & 119 & 0.2 & 5 & 0.5 & 17 & 0.4 & 26 & 0.2 & 71 & 0.2 \\
\hline \multicolumn{11}{|l|}{ Hospitalizations } \\
\hline None & 52,092 & 89.9 & 735 & 75.6 & 3676 & 85.0 & 11,206 & 88.8 & 36,475 & 91.1 \\
\hline $1-2$ & 5013 & 8.7 & 176 & 18.1 & 524 & 12.1 & 1190 & 9.4 & 3123 & 7.8 \\
\hline$\geq 3$ & 841 & 1.5 & 61 & 6.3 & 126 & 2.9 & 218 & 1.7 & 436 & 1.1 \\
\hline \multicolumn{11}{|c|}{ Townsend deprivation index } \\
\hline 1 (least deprived) & 11,719 & 20.2 & 146 & 15.0 & 752 & 17.4 & 2445 & 19.4 & 8376 & 20.9 \\
\hline 2 & 11,797 & 20.4 & 173 & 17.8 & 811 & 18.7 & 2515 & 19.9 & 8298 & 20.7 \\
\hline 3 & 11,672 & 20.1 & 214 & 22.0 & 884 & 20.4 & 2586 & 20.5 & 7988 & 20.0 \\
\hline 4 & 11,548 & 19.9 & 223 & 22.9 & 958 & 22.1 & 2486 & 19.7 & 7881 & 19.7 \\
\hline 5 (most deprived) & 8203 & 14.2 & 155 & 15.9 & 682 & 15.8 & 1875 & 14.9 & 5491 & 13.7 \\
\hline Unknown & 3007 & 5.2 & 61 & 6.3 & 239 & 5.5 & 707 & 5.6 & 2000 & 5.0 \\
\hline \multicolumn{11}{|l|}{ Practice location } \\
\hline Urban & 38,467 & 66.4 & 628 & 64.6 & 2862 & 66.2 & 8,443 & 66.9 & 26,534 & 66.3 \\
\hline Town & 6335 & 10.9 & 114 & 11.7 & 476 & 11.0 & 1,207 & 9.6 & 4,538 & 11.3 \\
\hline Rural & 3373 & 5.8 & 55 & 5.7 & 239 & 5.5 & 703 & 5.6 & 2,376 & 5.9 \\
\hline Unknown & 9771 & 16.9 & 175 & 18.0 & 749 & 17.3 & 2,261 & 17.9 & 6,586 & 16.5 \\
\hline
\end{tabular}

BMI, body mass index; eGFR, estimated glomerular filtration rate; $\mathrm{HbA}_{1 c}$ glycated hemoglobin; PCP, primary care physician.

Health Survey of England, which is a national population survey $[34,35]$.

Duration of diabetes was defined as the time interval between the first ever recorded entry for type 2 diabetes in the database (including treatment for diabetes) and the start date (date of the first ever valid recorded serum creatinine measurement). Duration of diabetes was categorized into five groups: < 1 year, 1-4 years, $5-9$ years, $10-14$ years and $\geq 15$ years.

\section{Estimated glomerular filtration rate}

The modification of diet in renal disease (MDRD) study formula and the Cockcroft-Gault formula are routinely used to calculate eGFR from serum creatinine concentration. In this study, the eGFR at baseline was calculated using the MDRD study formula $\left(\mathrm{eGFR}=186 \times \mathrm{Cr}^{-1.154} \times\right.$ age $^{-0.203} \times 1.212$ [if black] $\times$ 0.742 [if female], where $\mathrm{Cr}$ is the serum creatinine concentration in $\mathrm{mg} / \mathrm{dL}$ ). Ethnicity is not recorded in THIN, hence the same formula was used for all patients $\left(\mathrm{eGFR}=186 \times \mathrm{Cr}^{-1.154} \times\right.$ age $^{-0.203} \times 0.742$ [if female]) to classify them into five subgroups according to their baseline eGFR: $<15 \mathrm{~mL} / \mathrm{min}$ (CDK stage 5 ), 15-29 $\mathrm{mL} / \mathrm{min}$ (CKD stage 4 ), 30-44 $\mathrm{mL} / \mathrm{min}$ (CKD stage $3 \mathrm{~B}$ ), $45-59 \mathrm{~mL} / \mathrm{min}$ (CKD stage $3 \mathrm{~A}$ ) and $\geq$ $60 \mathrm{~mL} / \mathrm{min}$ (CKD stages 1 and 2, or no CKD).

\section{Myocardial infarction ascertainment}

An automatic computer search for specific Read codes was used for the ascertainment of MI cases. Previous studies using this method have shown a very high specificity for MI, resulting in a confirmation rate greater than $90 \%$ when validated with the PCP via a questionnaire [36]. Therefore, additional steps of validation of the ascertainment of MI cases, such as manual review of patients' profiles or validation with a questionnaire, were not carried out in the present study. A total of 3435 cases of MI were identified.

\section{Ischemic stroke ascertainment}

The predictive value of computer-detected IS/TIA is lower than that for other outcomes such as MI owing to the level of misclassification of diagnoses using Read codes. Therefore, we used a multistep approach to 
Table 2 Comorbidities recorded any time before the start date, overall and according to eGFR category

\begin{tabular}{|c|c|c|c|c|c|c|c|c|c|c|}
\hline & \multirow{2}{*}{\multicolumn{2}{|c|}{ Overall $(N=57,946)$}} & \multicolumn{8}{|c|}{ eGFR category (mL/min) } \\
\hline & & & \multicolumn{2}{|c|}{$15-29(n=972)$} & \multicolumn{2}{|c|}{$30-44(n=4326)$} & \multicolumn{2}{|c|}{$45-59(n=12,614)$} & \multicolumn{2}{|c|}{$\geq 60(n=40,034)$} \\
\hline & Number & $\%$ & Number & $\%$ & Number & $\%$ & Number & $\%$ & Number & $\%$ \\
\hline $\mathrm{Ml}$ & 5581 & 9.6 & 196 & 20.2 & 729 & 16.9 & 1499 & 11.9 & 3157 & 7.9 \\
\hline$I S / T \mid A$ & 5675 & 9.8 & 207 & 21.3 & 774 & 17.9 & 1677 & 13.3 & 3017 & 7.5 \\
\hline COPD & 2651 & 4.6 & 85 & 8.7 & 279 & 6.4 & 725 & 5.7 & 1562 & 3.9 \\
\hline Thyroid disease & 4932 & 8.5 & 145 & 14.9 & 595 & 13.8 & 1441 & 11.4 & 2751 & 6.9 \\
\hline Hypertension & 32,752 & 56.5 & 664 & 68.3 & 2931 & 67.8 & 8197 & 65.0 & 20,960 & 52.4 \\
\hline Renal hypertension & 29 & 0.1 & 4 & 0.4 & 7 & 0.2 & 6 & 0.0 & 12 & 0.0 \\
\hline Hyperlipidemia & 3998 & 6.9 & 323 & 33.2 & 891 & 20.6 & 1342 & 10.6 & 1442 & 3.6 \\
\hline DVT & 3429 & 5.9 & 106 & 10.9 & 373 & 8.6 & 933 & 7.4 & 2017 & 5.0 \\
\hline PAD & 3695 & 6.4 & 158 & 16.3 & 554 & 12.8 & 1026 & 8.1 & 1957 & 4.9 \\
\hline Anemia & 3561 & 6.1 & 178 & 18.3 & 539 & 12.5 & 949 & 7.5 & 1895 & 4.7 \\
\hline Atrial fibrillation & 3494 & 6.0 & 67 & 6.9 & 265 & 6.1 & 742 & 5.9 & 2420 & 6.0 \\
\hline Heart failure & 4011 & 6.9 & 73 & 7.5 & 313 & 7.2 & 853 & 6.8 & 2772 & 6.9 \\
\hline Peptic ulcer disease & 3676 & 6.3 & 89 & 9.2 & 354 & 8.2 & 880 & 7.0 & 2353 & 5.9 \\
\hline Chronic liver disease & 685 & 1.2 & 10 & 1.0 & 47 & 1.1 & 134 & 1.1 & 494 & 1.2 \\
\hline Gout & 3599 & 6.2 & 134 & 13.8 & 480 & 11.1 & 876 & 6.9 & 2109 & 5.3 \\
\hline Osteoporosis & 1253 & 2.2 & 37 & 3.8 & 148 & 3.4 & 386 & 3.1 & 682 & 1.7 \\
\hline Cancer & 5295 & 9.1 & 119 & 12.2 & 620 & 14.3 & 1434 & 11.4 & 3122 & 7.8 \\
\hline Anxiety & 6171 & 10.6 & 122 & 12.6 & 453 & 10.5 & 1354 & 10.7 & 4242 & 10.6 \\
\hline GERD & 6152 & 10.6 & 121 & 12.4 & 546 & 12.6 & 1493 & 11.8 & 3992 & 10.0 \\
\hline
\end{tabular}

COPD, chronic obstructive pulmonary disease; DVT, deep vein thrombosis; eGFR, estimated glomerular filtration rate; GERD, gastroesophageal reflux disease; IS, ischemic stroke; MI, myocardial infarction; PAD, peripheral arterial disease; TIA, transient ischemic attack.

ascertain IS/TIA cases (see Additional file 1 for a detailed description). Briefly, a computer search using Read codes suggestive of IS/TIA identified 4799 potential cases. Among these cases, 902 were matched to patients reviewed in other projects in which we looked at a diagnosis of IS/TIA in THIN [37,38]; 653 were classified as non-cases and 249 as cases. For the remaining 3897 patients, the cases of IS/TIA were ascertained in a stepwise fashion by first searching for indicators of hospitalization or referral and then searching for

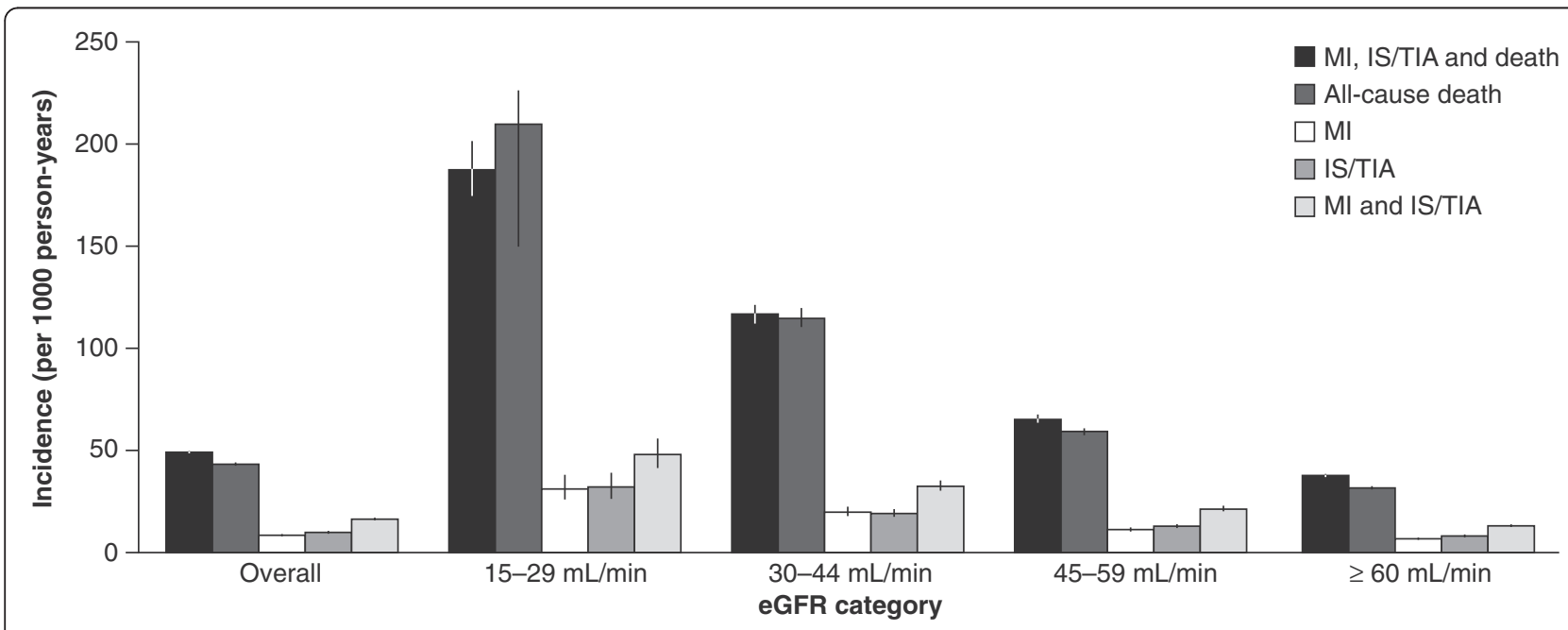

Figure 1 Incidence rates of death, myocardial infarction (MI) and ischemic stroke (IS)/transient ischemic attack (TIA). Incidence rates are shown both overall and according to estimated glomerular filtration rate (eGFR) category. Black vertical lines represent 95\% confidence intervals. 

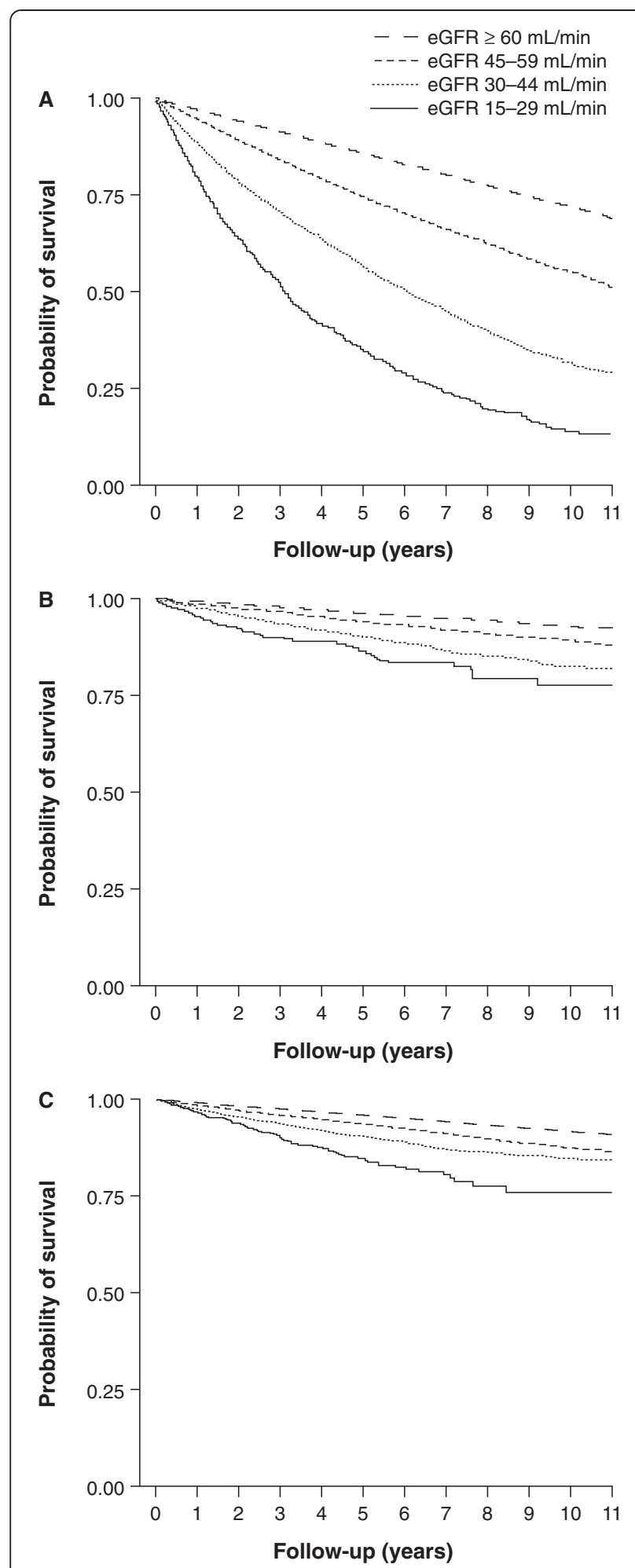

Figure 2 Kaplan-Meier survival estimates. Cumulative incidence of (A) death, (B) myocardial infarction and (C) ischemic stroke or transient ischemic attack according to estimated glomerular filtration rate (eGFR) category.
Table 3 HRs of death, MI and IS/TIA associated with eGFR category

\begin{tabular}{|c|c|c|c|}
\hline & $\begin{array}{l}\text { Death } \\
\operatorname{HR}^{\mathrm{a}}(95 \% \mathrm{Cl})\end{array}$ & $\begin{array}{l}\text { MI } \\
H^{a}(95 \% C l)\end{array}$ & $\begin{array}{l}\text { IS/TIA } \\
\operatorname{HR}^{\mathrm{a}}(95 \% \mathrm{Cl})\end{array}$ \\
\hline \multicolumn{4}{|c|}{ eGFR calculated with the MDRD study equation, $\mathrm{mL} / \mathrm{min}$} \\
\hline $15-29$ & $2.79(2.57-3.03)$ & $2.34(1.90-2.88)$ & $1.78(1.44-2.19)$ \\
\hline $30-59$ & $1.38(1.33-1.43)$ & $1.37(1.27-1.48)$ & $1.13(1.05-1.22)$ \\
\hline $30-44$ & $1.83(1.74-1.92)$ & $1.75(1.56-1.97)$ & $1.27(1.13-1.43)$ \\
\hline $45-59$ & $1.25(1.20-1.30)$ & $1.27(1.17-1.38)$ & $1.09(1.01-1.18)$ \\
\hline$\geq 60$ & $1(-)$ & $1(-)$ & $1(-)$ \\
\hline \multicolumn{4}{|c|}{ eGFR calculated with the CKD-EPI equation, $\mathrm{mL} / \mathrm{min}$} \\
\hline $15-29$ & $2.79(2.59-2.99)$ & $2.21(1.83-2.66)$ & $1.73(1.44-2.09)$ \\
\hline $30-59$ & $1.41(1.36-1.46)$ & $1.38(1.28-1.49)$ & $1.20(1.12-1.29)$ \\
\hline $30-44$ & $1.75(1.67-1.84)$ & $1.72(1.54-1.92)$ & $1.28(1.15-1.43)$ \\
\hline $45-59$ & $1.29(1.24-1.34)$ & $1.27(1.17-1.38)$ & $1.19(1.09-1.27)$ \\
\hline$\geq 60$ & $1(-)$ & $1(-)$ & $1(-)$ \\
\hline
\end{tabular}

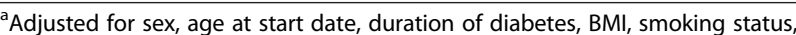
number of medications, $\mathrm{HbA}_{1 c}$ level, presence of hypertension hyperlidemia, and history of MI, IS/TIA and IHD.

$\mathrm{BMI}$, body mass index; $\mathrm{Cl}$, confidence interval; eGFR, estimated glomerular filtration rate; $\mathrm{HbA}_{1 c}$, glycated hemoglobin; $\mathrm{HR}$, hazard ratio; $\mathrm{IHD}$, ischemic heart disease; IS, ischemic stroke; MI, myocardial infarction; TIA, transient ischemic attack.

indicators of symptoms, diagnostic procedures and new treatment related to stroke in the 30 days before and after the date of the computer-detected IS/TIA. Finally, the profiles (including free text) of sample patients from different subgroups were manually reviewed to validate the ascertainment of cases. Overall, we identified 3785 cases of IS/TIA.

\section{Data collection}

Data on demographic variables including sex, age, smoking status, alcohol use, body mass index (BMI) and Townsend deprivation index (a measure of material deprivation within a population that takes into account four main variables: unemployment rate, car ownership, home ownership and household overcrowding) [39] were collected any time before the start date. Exposure to drugs was collected before the start date and categorized as follows: current use, when the supply of the most recent prescription lasted until the start date or ended in the 90 days before the start date; recent use, when supply of the most recent prescription ended more than 90 days before the start date; and non-use, when there was no recorded use any time before the start date. Data on healthcare service use (PCP visits, referrals and hospitalizations) were collected for the year before the start date. Information on comorbidities was collected any time before the start date. Data on levels of glycated hemoglobin $\left(\mathrm{HbA}_{1 \mathrm{c}}\right)$ were collected for the year before the start date. Patients were classified into 
Table 4 HRs of death associated with potential risk factors, overall and stratified by eGFR category

\begin{tabular}{|c|c|c|c|c|c|c|c|}
\hline & \multirow{3}{*}{$\begin{array}{l}\text { Non-death } \\
n=41,368 \\
\text { Number (\%) }\end{array}$} & \multirow{2}{*}{$\begin{array}{l}\text { Death } \\
n=16,578\end{array}$} & & \multicolumn{4}{|l|}{ eGFR category } \\
\hline & & & Overall & $15-29 \mathrm{~mL} / \mathrm{min}$ & $30-44 \mathrm{~mL} / \mathrm{min}$ & $45-59 \mathrm{~mL} / \mathrm{min}$ & $\geq 60 \mathrm{~mL} / \mathrm{min}$ \\
\hline & & Number (\%) & $\mathrm{HR}^{\mathrm{a}}(95 \% \mathrm{Cl})$ & $\mathrm{HR}^{\mathrm{b}}(95 \% \mathrm{Cl})$ & $\mathrm{HR}^{\mathrm{b}}(95 \% \mathrm{Cl})$ & $\mathrm{HR}^{\mathrm{b}}(95 \% \mathrm{Cl})$ & $\mathrm{HR}^{\mathrm{b}}(95 \% \mathrm{Cl})$ \\
\hline \multicolumn{8}{|l|}{ Sex } \\
\hline Men & $22,752(55.0)$ & $9365(56.5)$ & $1(-)$ & $1(-)$ & $1(-)$ & $1(-)$ & $1(-)$ \\
\hline Women & $18,616(45.0)$ & $7213(43.5)$ & $0.80(0.77-0.82)$ & $1.03(0.87-1.21)$ & $0.77(0.71-0.84)$ & $0.79(0.75-0.84)$ & $0.78(0.74-0.82)$ \\
\hline \multicolumn{8}{|c|}{ Age at start date (years) } \\
\hline $20-49$ & $5428(13.1)$ & $295(1.8)$ & $1(-)$ & $1(-)$ & $1(-)$ & $1(-)$ & $1(-)$ \\
\hline $50-74$ & $29,403(71.1)$ & $8669(52.3)$ & $3.90(3.47-4.39)$ & $0.60(0.25-1.48)$ & $2.62(1.24-5.54)$ & $2.43(1.62-3.63)$ & $3.75(3.30-4.25)$ \\
\hline$\geq 75$ & $6537(15.8)$ & $7614(45.9)$ & $11.24(9.97-12.67)$ & $0.97(0.40-2.40)$ & $5.12(2.43-10.80)$ & $6.40(4.27-9.58)$ & $13.01(11.42-14.83$ \\
\hline \multicolumn{8}{|c|}{ Duration of diabetes (years) } \\
\hline$<5$ & $20,135(48.7)$ & $5914(35.7)$ & $1(-)$ & $1(-)$ & $1(-)$ & $1(-)$ & $1(-)$ \\
\hline $5-9$ & $12,134(26.3)$ & 4989 (30.1) & $1.16(1.12-1.21)$ & $1.07(0.87-1.32)$ & $1.14(1.03-1.27)$ & $1.14(1.06-1.22)$ & $1.17(1.11-1.23)$ \\
\hline $10-14$ & $5497(13.3)$ & $3006(18.1)$ & $1.32(1.26-1.38)$ & $1.12(0.88-1.42)$ & $1.26(1.12-1.41)$ & $1.26(1.16-1.37)$ & $1.35(1.27-1.44)$ \\
\hline$\geq 15$ & $3602(8.7)$ & $2669(16.1)$ & $1.50(1.43-1.57)$ & $1.30(1.04-1.62)$ & $1.38(1.22-1.55)$ & $1.46(1.34-1.60)$ & $1.53(1.43-1.64)$ \\
\hline \multicolumn{8}{|l|}{$\mathrm{BMI}\left(\mathrm{kg} / \mathrm{m}^{2}\right)$} \\
\hline $15-19$ & $477(1.2)$ & $438(2.6)$ & $1.51(1.36-1.66)$ & $1.12(0.63-2.00)$ & $1.30(0.98-1.73)$ & $1.53(1.27-1.84)$ & $1.56(1.37-1.79)$ \\
\hline $20-24$ & $6127(14.8)$ & 3419 (20.6) & $1(-)$ & $1(-)$ & $1(-)$ & $1(-)$ & $1(-)$ \\
\hline $25-29$ & $15,249(36.9)$ & $5762(34.8)$ & $0.78(0.75-0.82)$ & $0.72(0.57-0.90)$ & $0.82(0.73-0.92)$ & $0.79(0.73-0.86)$ & $0.78(0.73-0.83)$ \\
\hline$\geq 30$ & $17,577(42.5)$ & $5382(32.5)$ & $0.82(0.78-0.85)$ & $0.64(0.51-0.81)$ & $0.80(0.71-0.90)$ & $0.85(0.78-0.92)$ & $0.82(0.77-0.87)$ \\
\hline Unknown & $1938(4.7)$ & $1577(9.5)$ & $1.43(1.34-1.52)$ & $1.17(0.88-1.55)$ & $1.32(1.13-1.54)$ & $1.54(1.37-1.72)$ & $1.42(1.30-1.56)$ \\
\hline \multicolumn{8}{|l|}{ Smoking status } \\
\hline Non-smoker & $21,930(53.0)$ & $8245(49.7)$ & $1(-)$ & $1(-)$ & $1(-)$ & $1(-)$ & $1(-)$ \\
\hline Current & $6819(16.5)$ & $3309(20.0)$ & $1.50(1.44-1.57)$ & $1.09(0.84-1.40)$ & $1.33(1.18-1.50)$ & $1.60(1.48-1.74)$ & $1.54(1.46-1.63)$ \\
\hline Former & $10,815(26.1)$ & $4196(25.3)$ & $1.07(1.03-1.12)$ & $1.04(0.86-1.25)$ & $1.00(0.91-1.11)$ & $1.09(1.02-1.17)$ & $1.08(1.03-1.14)$ \\
\hline Unknown & $1804(4.4)$ & $828(5.0)$ & $0.95(0.88-1.02)$ & $1.06(0.78-1.45)$ & $0.88(0.73-1.06)$ & $1.00(0.86-1.15)$ & $0.91(0.82-1.01)$ \\
\hline \multicolumn{8}{|c|}{ Number of medications } \\
\hline $0-1$ & $11,963(28.9)$ & 3044 (18.4) & $1(-)$ & $1(-)$ & $1(-)$ & $1(-)$ & $1(-)$ \\
\hline $2-4$ & $15,169(36.7)$ & 5289 (31.9) & $1.21(1.15-1.26)$ & $0.90(0.67-1.20)$ & $1.07(0.94-1.23)$ & $1.19(1.09-1.30)$ & $1.22(1.16-1.30)$ \\
\hline $5-9$ & $12,235(29.6)$ & 6445 (38.9) & $1.45(1.39-1.52)$ & $1.02(0.79-1.32)$ & $1.15(1.01-1.31)$ & $1.39(1.27-1.51)$ & $1.53(1.44-1.63)$ \\
\hline$\geq 10$ & $2001(4.8)$ & $1800(10.9)$ & $2.03(1.91-2.16)$ & $1.03(0.76-1.39)$ & $1.67(1.43-1.96)$ & $2.01(1.79-2.26)$ & $2.18(1.99-2.38)$ \\
\hline \multicolumn{8}{|l|}{$\mathrm{HbA}_{1 \mathrm{c}}(\%)$} \\
\hline$<7.00$ & $14,151(34.2)$ & 5231 (31.6) & $1(-)$ & $1(-)$ & $1(-)$ & $1(-)$ & $1(-)$ \\
\hline $7.00-7.99$ & 9363 (22.6) & $3460(20.9)$ & $1.01(0.97-1.05)$ & $1.29(1.03-1.61)$ & $1.04(0.92-1.16)$ & $0.98(0.91-1.06)$ & $1.01(0.95-1.07)$ \\
\hline $8.00-8.99$ & $5333(12.9)$ & $1888(11.4)$ & $0.97(0.92-1.02)$ & $1.02(0.77-1.36)$ & $1.12(0.97-1.29)$ & $0.96(0.87-1.07)$ & $0.95(0.88-1.02)$ \\
\hline $9.00-9.99$ & $3319(8.0)$ & $1315(7.9)$ & $1.14(1.07-1.21)$ & $1.40(1.01-1.92)$ & $1.24(1.05-1.46)$ & $1.18(1.04-1.32)$ & $1.11(1.02-1.20)$ \\
\hline$\geq 10.00$ & $3363(8.1)$ & $1435(8.7)$ & $1.35(1.27-1.43)$ & $1.23(0.92-1.65)$ & $1.46(1.23-1.73)$ & $1.43(1.27-1.60)$ & $1.31(1.21-1.42)$ \\
\hline Missing & $5839(14.1)$ & 3249 (19.6) & $1.24(1.19-1.30)$ & $1.35(1.09-1.67)$ & $1.38(1.23-1.54)$ & $1.19(1.09-1.30)$ & $1.23(1.16-1.31)$ \\
\hline \multicolumn{8}{|l|}{ Comorbidities $^{c}$} \\
\hline Hypertension & $23,223(56.1)$ & 9529 (57.5) & $0.87(0.84-0.90)$ & $0.68(0.58-0.81)$ & $0.76(0.70-0.83)$ & $0.85(0.80-0.90)$ & $0.91(0.87-0.95)$ \\
\hline Hyperlipidemia & $1343(3.2)$ & 2655 (16.0) & $2.04(1.95-2.13)$ & $1.68(1.42-1.98)$ & $1.76(1.59-1.93)$ & $2.13(1.97-2.31)$ & $2.33(2.16-2.51)$ \\
\hline History of Ml & $3033(7.3)$ & $2548(15.4)$ & $1.14(1.09-1.19)$ & $1.14(0.94-1.39)$ & $1.14(1.02-1.27)$ & $1.09(1.00-1.19)$ & $1.20(1.12-1.28)$ \\
\hline History of IS/TIA & $2776(6.7)$ & 2899 (17.5) & $1.51(1.45-1.57)$ & $1.12(0.93-1.36)$ & $1.39(1.26-1.54)$ & $1.46(1.36-1.57)$ & $1.67(1.57-1.77)$ \\
\hline History of IHD & $6146(14.9)$ & $4052(24.4)$ & $1.02(0.98-1.06)$ & $1.10(0.93-1.30)$ & $0.92(0.84-1.02)$ & $1.01(0.94-1.08)$ & $1.03(0.97-1.09)$ \\
\hline COPD & 1075 (2.6) & $1576(9.5)$ & $1.77(1.68-1.87)$ & $1.55(1.20-2.01)$ & $1.32(1.14-1.54)$ & $1.65(1.49-1.83)$ & $1.95(1.81-2.10)$ \\
\hline
\end{tabular}


Table 4 HRs of death associated with potential risk factors, overall and stratified by eGFR category (Continued)

\begin{tabular}{llllllll}
\hline Thyroid disease & $3418(8.3)$ & $1514(9.1)$ & $0.92(0.87-0.97)$ & $0.97(0.77-1.21)$ & $0.89(0.79-1.01)$ & $0.98(0.90-1.08)$ & $0.90(0.83-0.98)$ \\
DVT & $2138(5.2)$ & $1291(7.8)$ & $1.12(1.06-1.19)$ & $0.97(0.76-1.23)$ & $1.10(0.96-1.27)$ & $1.04(0.94-1.15)$ & $1.17(1.08-1.27)$ \\
PAD & $1742(4.2)$ & $1953(11.8)$ & $1.35(1.28-1.42)$ & $1.01(0.82-1.24)$ & $1.19(1.06-1.33)$ & $1.41(1.29-1.55)$ & $1.44(1.34-1.55)$ \\
Anemia & $2097(5.1)$ & $1464(8.8)$ & $1.24(1.17-1.31)$ & $1.05(0.86-1.28)$ & $1.26(1.12-1.41)$ & $1.23(1.11-1.36)$ & $1.29(1.18-1.40)$ \\
Atrial fibrillation & $2483(6.0)$ & $1011(6.1)$ & $1.01(0.95-1.07)$ & $1.04(0.76-1.41)$ & $0.98(0.83-1.16)$ & $1.05(0.93-1.18)$ & $1.00(0.91-1.09)$ \\
Heart failure & $2850(6.9)$ & $1161(7.0)$ & $1.02(0.96-1.08)$ & $1.07(0.79-1.44)$ & $1.03(0.88-1.20)$ & $1.04(0.93-1.17)$ & $0.99(0.91-1.08)$ \\
Gout & $2370(5.7)$ & $1229(7.4)$ & $0.98(0.92-1.04)$ & $0.95(0.76-1.19)$ & $0.98(0.86-1.12)$ & $0.99(0.88-1.10)$ & $1.00(0.92-1.10)$ \\
Cancer & $2948(7.1)$ & $2347(14.2)$ & $1.49(1.42-1.55)$ & $1.50(1.20-1.88)$ & $1.19(1.07-1.34)$ & $1.34(1.23-1.45)$ & $1.67(1.57-1.78)$ \\
\hline
\end{tabular}

${ }^{a}$ Adjusted for sex, age at start date, duration of diabetes, BMI, smoking status, number of medications, HbA1c level, presence of hypertension hyperlidemia, and history of MI, IS/TIA, IHD. and eGFR category. ${ }^{b}$ Adjusted for sex, age at start date, duration of diabetes, BMI, smoking status, number of medications, HbA1c level, presence of hypertension hyperlidemia, and history of MI, IS/TIA and IHD. 'Relative to absence of comorbidity. ${ }^{\mathrm{d}}$ Excluding MI.

$\mathrm{BMI}$, body mass index; $\mathrm{Cl}$, confidence interval; COPD, chronic obstructive pulmonary disease; DVT, deep vein thrombosis; eGFR, estimated glomerular filtration rate; $\mathrm{HbA}_{1 c}$, glycated hemoglobin; HR, hazard ratio; IHD, ischemic heart disease; IS, ischemic stroke; MI, myocardial infarction; PAD, peripheral artery disease; TIA, transient ischemic attack.

subgroups according to the $\mathrm{HbA}_{1 \mathrm{c}}$ data recorded closest to their start date: < 7.00\%, 7.00-7.99\%, 8.00-8.99\%, $9.00-9.99 \%, \quad 10.00-10.99 \%$ and $\geq 11.00 \%$. Individuals without a recorded level of $\mathrm{HbA}_{1 \mathrm{c}}$ in the year before their start date were included in the 'missing' category.

\section{Statistical analysis}

Incidence rates of death, MI and IS/TIA were calculated overall and by eGFR categories. Kaplan-Meier survival curves for all-cause mortality, MI and IS/TIA were calculated overall and according to eGFR category. Hazard ratios (HRs) and their 95\% confidence intervals (CIs) were calculated using Cox proportional hazard models adjusted for sex, age, BMI, smoking status, hyperlipidemia, hypertension, history of MI, history of IS/TIA, history of ischemic heart disease (excluding MI), eGFR category, duration of diabetes, $\mathrm{HbA}_{1 \mathrm{c}}$ category, and polypharmacy (in the month before the start date). A two-sided $p$ value $<0.05$ was considered to be statistically significant. Statistical analyses were performed using the Stata package version 12.0 (StataCorp LP, College Station, TX, USA).

\section{Results}

\section{Baseline characteristics and comorbidities}

Table 1 shows the main baseline characteristics of patients with type 2 diabetes included in this study, according to their eGFR category. Almost $70 \%$ of patients had an eGFR $\geq 60 \mathrm{~mL} / \mathrm{min}$ and about $9 \%$ had an eGFR of $15-44 \mathrm{~mL} / \mathrm{min}$ (CKD stages $3 \mathrm{~B}$ and 4 ). Overall, the mean age at start date was 65.7 years and there were more men than women in the study cohort (55.4\% and $44.6 \%$, respectively). However, there were more women than men in the subgroup of patients with an eGFR $<60 \mathrm{~mL} / \mathrm{min}(58.7 \%$ and $41.3 \%$, respectively). Over $75 \%$ of patients were overweight or obese $\left(\mathrm{BMI} \geq 25 \mathrm{~kg} / \mathrm{m}^{2}\right)$ and over $65 \%$ were using 2-9 drugs in the month before their start date. About $70 \%$ of patients had had diabetes for 1-9 years at their start date, whereas about $5 \%$ had had diabetes for $<1$ year. Among patients with a record of $\mathrm{HbA}_{1 \mathrm{c}}$ level, about $60 \%(29,476 / 48,858)$ had an $\mathrm{HbA}_{1 \mathrm{c}}$ level $\geq 7 \%$.

Among the comorbidities we assessed (Table 2), hypertension was the most prevalent; over $55 \%$ of patients had hypertension. The proportion was highest among individuals with an eGFR of $15-29 \mathrm{~mL} / \mathrm{min}$ (68.3\%). A history of MI or IS/TIA was recorded in $9.6 \%$ and $9.8 \%$ of patients, respectively. Other frequent comorbidities included cancer (9.1\%), hyperlipidemia (6.9\%), heart failure (6.9\%), peripheral artery disease (6.4\%), atrial fibrillation (6.0\%) and deep vein thrombosis $(5.9 \%)$. The prevalence of comorbidities tended to be higher in patients with lower eGFRs; about a third of those with an eGFR of 15-29 $\mathrm{mL} / \mathrm{min}$ (CKD stage 4) had hyperlipidemia.

Incidences of death, myocardial infarction and stroke Incidence rates of death, MI, IS/TIA and combined outcomes stratified by eGFR category and overall are shown in Figure 1.

\section{Mortality}

A total of 16,578 (28.6\%) patients died during the study period. The person-time contribution was 379,833 person-years over a median follow-up time of 6.76 years. The overall mortality was 43.65 deaths per 1000 personyears (95\% CI: 42.99-44.31). There was a marked increase in all-cause mortality with decreasing values of eGFR. Patients with an eGFR of $15-29 \mathrm{~mL} / \mathrm{min}$ (CDK stage 4) showed the highest mortality (210.01 deaths per 1000 person-years [95\% CI: 149.91-226.28]), whereas those with an eGFR $\geq 60 \mathrm{~mL} / \mathrm{min}$ showed the lowest mortality (31.99 deaths per 1000 person-years [95\% CI: 31.33-32.66]). Kaplan-Meier curves of cumulative incidence of death are shown in Figure 2A. 
Table 5 HRs of MI associated with potential risk factors, overall and stratified by eGFR category




Table 5 HRs of MI associated with potential risk factors, overall and stratified by eGFR category (Continued)

\begin{tabular}{llllllll}
\hline Thyroid disease & $4648(8.5)$ & $284(8.3)$ & $0.96(0.85-1.09)$ & $1.37(0.80-2.36)$ & $0.86(0.64-1.17)$ & $0.91(0.73-1.13)$ & $1.01(0.84-1.21)$ \\
DVT & $3199(5.9)$ & $230(6.7)$ & $1.03(0.90-1.18)$ & $0.43(0.19-0.98)$ & $1.03(0.73-1.46)$ & $0.88(0.68-1.15)$ & $1.17(0.97-1.40)$ \\
PAD & $3253(6.0)$ & $442(12.9)$ & $1.53(1.38-1.70)$ & $1.15(0.70-1.91)$ & $1.55(1.20-2.00)$ & $1.40(1.14-1.71)$ & $1.67(1.45-1.93)$ \\
Anemia & $3310(6.1)$ & $251(7.3)$ & $1.12(0.98-1.28)$ & $1.04(0.63-1.73)$ & $0.93(0.68-1.27)$ & $1.18(0.94-1.50)$ & $1.18(0.97-1.44)$ \\
Atrial fibrillation & $3273(6.0)$ & $221(6.4)$ & $1.08(0.95-1.24)$ & $0.96(0.41-2.24)$ & $0.77(0.49-1.22)$ & $1.07(0.81-1.41)$ & $1.17(0.99-1.39)$ \\
Heart failure & $3759(6.9)$ & $252(7.3)$ & $1.06(0.93-1.21)$ & $0.83(0.39-1.79)$ & $0.59(0.37-0.95)$ & $1.02(0.79-1.32)$ & $1.21(1.03-1.42)$ \\
Gout & $3359(6.2)$ & $240(7.0)$ & $0.93(0.81-1.06)$ & $1.25(0.72-2.20)$ & $0.81(0.57-1.13)$ & $1.17(0.92-1.49)$ & $0.83(0.68-1.01)$ \\
Cancer & $4986(9.1)$ & $309(9.0)$ & $1.00(0.89-1.13)$ & $1.61(0.92-2.85)$ & $0.83(0.60-1.14)$ & $1.07(0.87-1.32)$ & $0.97(0.82-1.15)$ \\
\hline
\end{tabular}

${ }^{a}$ Adjusted for sex, age at start date, duration of diabetes, BMI, smoking status, number of medications, HbA1c level, presence of hypertension hyperlidemia, and

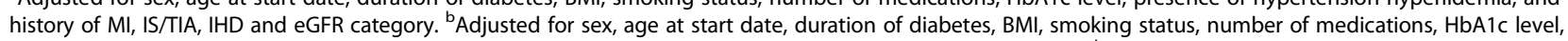
presence of hypertension hyperlidemia, and history of MI, IS/TIA, and IHD. ${ }^{\mathrm{C}}$ Relative to absence of comorbidity. ${ }^{\mathrm{d}} \mathrm{Excluding} \mathrm{MI}$.

$\mathrm{BMI}$, body mass index; $\mathrm{Cl}$, confidence interval; COPD, chronic obstructive pulmonary disease; DVT, deep vein thrombosis; eGFR, estimated glomerular filtration rate; $\mathrm{HbA}_{1 c}$, glycated hemoglobin; HR, hazard ratio; IHD, ischemic heart disease; IS, ischemic stroke; MI, myocardial infarction; PAD, peripheral artery disease; TIA, transient ischemic attack.

\section{Incidence of myocardial infarction}

The overall incidence rate of MI was 9.26 cases per 1000 person-years (95\% CI: 8.96-9.58) over a median follow-up time of 6.64 years. As for mortality, the incidence rate of MI increased with decreasing values of eGFR. The incidence rates of MI for patients with an eGFR of $15-29 \mathrm{~mL} / \mathrm{min}$ (CKD stage 4) and $\geq 60 \mathrm{~mL} / \mathrm{min}$ were 31.65 (95\% CI: 26.02-38.51) and 7.44 (95\% CI: 7.12-7.77) cases per 1000 person-years, respectively. Kaplan-Meier curves of cumulative incidence of MI are shown in Figure 2B.

Incidence of ischemic stroke and transient ischemic attack The overall incidence rate of IS/TIA was 10.39 cases per 1000 person-years (95\% CI: 10.07-10.73) with a median follow-up time of 6.56 years and a person-time contribution of 364,258 person-years. An increased incidence rate of IS/TIA was observed with declining renal function. The incidence rates of IS/TIA were 32.48 cases per 1000 person-years (95\% CI: 26.7039.51 ) in patients with CKD stage 4 (eGFRs of $15-$ $29 \mathrm{~mL} / \mathrm{min})$ and 8.65 cases per 1000 person-years $(95 \%$ CI: 8.30-9.00) in patients with an eGFR $\geq 60 \mathrm{~mL} / \mathrm{min}$. Kaplan-Meier curves of cumulative incidence of IS/ TIA are shown in Figure 2C.

\section{Cox regression analyses}

Risks of death, MI and IS/TIA increased significantly with decreasing values of eGFR (Table 3). For patients with eGFR 15-29 $\mathrm{mL} / \mathrm{min}$ (CKD stage 4 ), the adjusted HRs relative to patients with an eGFR $\geq 60 \mathrm{~mL} / \mathrm{min}$ were 2.79 (95\% CI: 2.57-3.03) for death, 2.33 (95\% CI: 1.89-2.87) for MI and 1.77 (95\% CI: 1.43-2.18) for IS/ TIA. Corresponding estimates for patients with eGFRs of $45-59 \mathrm{~mL} / \mathrm{min}$ were 1.25 (95\% CI: $1.20-1.30), 1.27$ (95\% CI: 1.17-1.38) and 1.09 (95\% CI: 1.01-1.18).

HRs for death, MI and IS/TIA associated with other potential risk factors are shown in Tables 4, 5 and 6. Overall, women had a lower risk of death and of MI than men (HR: 0.80 [95\% CI: 0.77-0.82] and HR: 0.71 [95\% CI: 0.66-0.77], respectively) and the risk of IS/ TIA was similar for men and women. For each outcome, a longer duration of diabetes was generally associated with a greater risk. Overall, the HRs associated with diabetes diagnosed more than 15 years before the start date relative to diabetes diagnosed less than 5 years before the start date were 1.50 (95\% CI: $1.43-$ 1.57) for death, 1.54 (95\% CI: 1.39-1.71) for MI and 1.27 (95\% CI: 1.15-1.41) for IS/TIA. Age was a strong predictor of death, MI and IS/TIA. The HRs for patients aged 75 years or older relative to patients aged 20-49 years were 11.24 (95\% CI: 9.97-12.67), 2.99 (95\% CI: 2.49-3.59) and 5.33 (95\% CI: 4.35-6.54) for death, MI and IS/TIA, respectively. BMI did not affect the risk of MI or IS/TIA significantly. The risk of death, however, was significantly lower for overweight patients (BMI of $25-29 \mathrm{~kg} / \mathrm{m}^{2}$ ) and obese patients $\left(B M I \geq 30 \mathrm{~kg} / \mathrm{m}^{2}\right)$ than for individuals with a BMI of 20-24 kg/m² (HR: 0.78 [95\% CI: 0.75-0.82] and HR 0.82 [95\% CI: 0.78-0.85], respectively). Conversely, underweight patients (BMI of $15-19 \mathrm{~kg} / \mathrm{m}^{2}$ ) were at higher risk of death than individuals with a BMI of 20$24 \mathrm{~kg} / \mathrm{m}^{2}$ (HR: 1.51 [95\% CI: 1.36-1.66]).

Patients with a history of MI had a greater risk of MI (HR: 1.94 [95\% CI: 1.77-2.12]) than patients without such a history. Similarly, a history of IS/TIA was a strong predictor of recurrent IS/TIA (HR: 3.27 [95\% CI: 3.03-3.53]). Hyperlipidemia was associated with an increased risk of death (HR: 2.03 [95\% CI: 1.94-2.13]), MI (HR: 1.39 [95\% CI: 1.25-1.56]) and IS/TIA (HR: 1.23 [95\% CI: 1.09-1.38]), but hypertension was not. A general trend for increased risk of death, MI and IS/TIA associated with increasing $\mathrm{HbA}_{1 \mathrm{c}}$ levels was observed. For patients with $\mathrm{HbA}_{1 \mathrm{c}}$ levels $\geq 11 \%$, the adjusted HRs relative to patients with $\mathrm{HbA}_{1 \mathrm{c}}$ levels $<7 \%$ were $1.43(95 \%$ CI: 1.33-1.55) for death, 1.63 (95\% CI: 1.37-1.93) for MI and 1.66 (95\% CI: 1.42-1.94) for IS/TIA. 
Table 6 HRs of IS or TIA associated with potential risk factors, overall and stratified by eGFR category




Table 6 HRs of IS or TIA associated with potential risk factors, overall and stratified by eGFR category (Continued)

\begin{tabular}{llllllll}
\hline Thyroid disease & $4571(8.4)$ & $361(9.5)$ & $1.01(0.90-1.13)$ & $0.72(0.40-1.31)$ & $0.97(0.72-1.29)$ & $0.99(0.81-1.21)$ & $1.07(0.91-1.25)$ \\
DVT & $3139(5.8)$ & $290(7.7)$ & $1.15(1.02-1.29)$ & $0.67(0.32-1.39)$ & $1.50(1.09-2.07)$ & $1.30(1.05-1.60)$ & $1.02(0.85-1.21)$ \\
PAD & $3330(6.1)$ & $365(9.6)$ & $1.22(1.09-1.36)$ & $0.96(0.54-1.68)$ & $1.35(1.02-1.77)$ & $1.36(1.11-1.67)$ & $1.15(0.98-1.35)$ \\
Anemia & $3298(6.1)$ & $263(6.9)$ & $1.04(0.92-1.19)$ & $0.82(0.47-1.44)$ & $1.01(0.74-1.38)$ & $1.05(0.83-1.33)$ & $1.08(0.90-1.30)$ \\
Atrial fibrillation & $3273(6.0)$ & $221(5.8)$ & $0.95(0.83-1.09)$ & $0.61(0.22-1.68)$ & $0.82(0.52-1.29)$ & $0.85(0.63-1.13)$ & $1.05(0.89-1.24)$ \\
Heart failure & $3755(6.9)$ & $256(6.8)$ & $0.97(0.86-1.11)$ & $0.76(0.30-1.91)$ & $1.08(0.74-1.57)$ & $1.06(0.83-1.34)$ & $0.95(0.80-1.12)$ \\
Gout & $3299(6.1)$ & $300(7.9)$ & $1.17(1.04-1.32)$ & $0.86(0.47-1.59)$ & $1.15(0.84-1.59)$ & $1.34(1.07-1.66)$ & $1.11(0.94-1.32)$ \\
Cancer & $4845(8.9)$ & $450(11.9)$ & $1.30(1.18-1.44)$ & $0.84(0.42-1.69)$ & $1.33(1.01-1.75)$ & $1.09(0.90-1.33)$ & $1.43(1.25-1.63)$ \\
\hline
\end{tabular}

${ }^{a}$ Adjusted for sex, age at start date, duration of diabetes, BMI, smoking status, number of medications, HbA1c level, presence of hypertension hyperlidemia, and

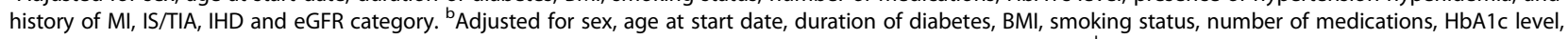
presence of hypertension hyperlidemia, and history of MI, IS/TIA, and IHD. ${ }^{\mathrm{C}}$ Relative to absence of comorbidity. ${ }^{\mathrm{d}}$ Excluding MI.

$\mathrm{BMI}$, body mass index; $\mathrm{Cl}$, confidence interval; COPD, chronic obstructive pulmonary disease; DVT, deep vein thrombosis; eGFR, estimated glomerular filtration rate; $\mathrm{HbA}_{1 \mathrm{c}}$, glycated hemoglobin; HR, hazard ratio; IHD, ischemic heart disease; IS, ischemic stroke; MI, myocardial infarction; PAD, peripheral artery disease; TIA TIA, transient ischemic attack.

\section{Discussion}

In a large population of patients with type 2 diabetes, incidence rates of death and cardiovascular events for each eGFR category were higher than those reported for patients with CKD in the general population [1], suggesting that diabetes adds to the burden of CKD. This may be explained in part by the higher prevalence of known risk factors for death and cardiovascular events in patients with diabetes and impaired renal function, including obesity, hypertension, hyperlipidemia and history of cardiovascular events.

In the present study, a reduced eGFR was a strong and independent risk factor for death and cardiovascular events. The association between lower eGFRs and increased all-cause mortality was consistent with observations from previous studies in various populations of patients with diabetes $[1,20-26]$. An association between renal impairment and increased risk of cardiovascular events was also observed in an observational study from the Swedish National Diabetes Register [25]. This study, however, excluded patients with CKD stages 4 and $5(e G F R<30 \mathrm{~mL} / \mathrm{min})$. Reduced eGFR was also identified as a risk factor for cardiovascular events in a small US population of patients with type 2 diabetes [26]. These observations may be explained by common features in the pathophysiologies of CKD and type 2 diabetes. Risk factors for cardiovascular events such as increased levels of procoagulant biomarkers, anemia and endothelial dysfunction have been shown to be associated with both reduced kidney function [40-42] and type 2 diabetes [43-45]. These factors may act synergistically to increase the risk of cardiovascular events compared with CKD or type 2 diabetes alone. The association of renal disease with hypoglycemia in patients with type 2 diabetes is also linked to an increased risk of cardiovascular events [46].

Our study also showed that age and duration of diabetes were predictors of all-cause mortality and incidence of cardiovascular events, irrespective of eGFR. This is in line with results from others [47] and suggests that, as the population ages and survival of patients with diabetes increases, further efforts will be required to complement ongoing measures to reduce all-cause mortality and risk of cardiovascular complications and in patients with type 2 diabetes. Traditional cardiovascular risk factors, including smoking, hyperlipidemia and a history of cardiovascular events, were also associated with an increased risk of cardiovascular events and a higher mortality in patients with type 2 diabetes. These findings echoed results from other population-based studies [48,49].

In contrast, overweight and obese people $(\mathrm{BMI} \geq$ $25 \mathrm{~kg} / \mathrm{m}^{2}$ ) had a lower mortality than individuals with a BMI of $20-24 \mathrm{~kg} / \mathrm{m}^{2}$. Although counterintuitive and controversial, this 'obesity paradox' has been observed in several cohort studies, patient registries and clinical trial populations [50].

Overall, our results support the current UK guidelines [51], which recommend monitoring renal function annually in all individuals with type 2 diabetes, regardless of the presence or absence of nephropathy. The guidelines also recommend addressing traditional cardiovascular risk factors such as hyperlipidemia and smoking, which we found to be associated with higher risks of death, MI and IS/TIA in this population.

The present study has several strengths. THIN is a large database representative of the UK population and has been validated for use in epidemiological studies $[29,30]$. It has previously been used to study individuals with diabetes [3,52-54] and patients with CKD [31]. The suitability of THIN for this study is reinforced by the fact that laboratory test results are reliably and routinely recorded in the database; $90 \%$ of patients in our large and diverse cohort had a valid serum creatinine measurement. Our results from a primary care database may also be more generalizable than studies from selected populations such as referred 
patients, recruited cohorts or clinical trial participants. Other strengths of our study include a long follow-up period and careful ascertainment of MI and IS/TIA cases. This was deemed particularly important for IS/ TIA in order to mitigate the observed tendency of Read codes to overestimate the number of IS/TIA cases. In common with all observational studies, however, ours may suffer from uncontrolled confounding. Although we tried to minimize this by adjusting results for several potential risk factors, residual confounding cannot be ruled out. It should also be noted that the levels of urine albumin were not systematically reported in THIN during the study period and it was therefore impossible to adjust analyses for this potential confounder $[55,56]$.

NICE guidelines on the management of CKD were updated in January 2015 and now recommend the use of the CKD-EPI equation for the calculation of eGFR from serum creatinine concentration [57]. During the study period (2000-2005), however, the MDRD and the Cockcroft-Gault equations were routinely used; the MDRD equation was used in THIN and recommended by NICE and was therefore selected for the present study. Additionally, the MDRD equation has been shown to be more accurate than the CockcroftGault formula in patients with CKD and diabetes [58]. The MDRD equation has also previously been used in a study of CKD in THIN [31]. It should be noted, however, that eGFR was calculated from a single serum creatinine measurement. To estimate the extent of eGFR misclassification, patients with a valid serum creatinine concentration recorded between 91 and 366 days after their start date were identified ( $\mathrm{n}=$ $47,022,81 \%$ of the study population). Among those patients, 14,528 had an eGFR $<60 \mathrm{~mL} / \mathrm{min}$ on their start date, and the diagnosis of impaired renal function was confirmed by subsequent creatinine measurement in 12,055 individuals $(83 \%)$. Conversely, $90 \%$ of patients $(\mathrm{n}=29,240)$ who had an eGFR $\geq 60 \mathrm{~mL} / \mathrm{min}$ on their start date and who had a valid creatinine measurement in the 91-366-day period following their start date remained in the same eGFR category. The fact that ethnicity is not recorded in THIN may also have led to misclassification; eGFR may have been underestimated in black people.

\section{Conclusions}

In conclusion, this retrospective study based on a UK primary care database confirms the high prevalence of impaired renal function in patients with type 2 diabetes. Our findings show that all-cause mortality and the risk of cardiovascular events increase significantly with decreasing values of eGFR. In line with current UK guidelines for the treatment of type 2 diabetes, our results suggest that physicians should closely monitor renal function in patients with type 2 diabetes and initiate lifestyle changes and/or medication to delay progression of CKD and prevent end-stage renal disease. Management of associated cardiovascular risks such as hyperlipidemia and smoking should also be adequately addressed, given the very high risk of adverse cardiovascular events in patients with both type 2 diabetes and impaired renal function.

\section{Ethics, consent and permissions}

We used The Health Improvement Network (THIN) primary care data for this study. The company that owns THIN (Cegedim Strategic Data Medical Research) has received ethical approval from the South East Research Ethics Committee (REC) to supply anonymized, pre-collected primary care data for scientific research. Patients can opt out of having their depersonalized records collected and therefore patient consent is not required when working with anonymized records in the THIN database.

\section{Additional file}

\section{Additional file 1: Ischemic stroke ascertainment.}

\section{Abbreviations}

BMI: Body mass index; Cl: Confidence interval; CKD: Chronic kidney disease; EGFR: Estimated glomerular filtration rate; $\mathrm{HbA}_{1 c}$ : Glycated hemoglobin; HR: Hazard ratio; IS/TIA: Ischemic stroke or transient ischemic attack; MDRD: Modification of diet in renal disease; MI: Myocardial infarction; MREC: Multicentre Research Ethics Committee; PCP: Primary care physician; THIN: The Health Improvement Network.

\section{Competing interests}

LCS and LAGR work for CEIFE, which has received research funding from AstraZeneca R\&D, Mölndal, Sweden and Bayer Pharma AG, Berlin, Germany. LAGR has also received honoraria for serving on scientific advisory boards for AstraZeneca and Bayer. SJ and BS are employees of AstraZeneca R\&D, Mölndal, Sweden.

\section{Authors' contributions}

LCS and LAGR designed the study and performed the statistical analysis. SJ and BS provided input on the design of the study. All four authors were involved in analysis and interpretation of the data. All four authors revised the intellectual content of the manuscript and approved the final version.

\section{Acknowledgments}

Medical writing support was provided by Dr Stéphane Pintat of Oxford PharmaGenesis, Oxford, UK, and was funded by AstraZeneca R\&D, Mölndal, Sweden.

The study was funded with financial research support from AstraZeneca R\&D, Mölndal, Sweden and part of the results were presented in poster format at the European Association for the Study of Diabetes Congress, 15-19 September 2014, Vienna, Austria.

\section{Author details}

'Spanish Centre for Pharmacoepidemiologic Research (CEIFE), Almirante 28-2, E 28004 Madrid, Spain. ${ }^{2}$ AstraZeneca R\&D, Mölndal, Sweden.

Received: 9 January 2015 Accepted: 3 April 2015

Published online: 18 April 2015

\section{References}

1. Go AS, Chertow GM, Fan D, McCulloch CE, Hsu CY. Chronic kidney disease and the risks of death, cardiovascular events, and hospitalization. N Engl J Med. 2004;351:1296-305. 
2. Fox CS, Coady S, Sorlie PD, Levy D, Meigs JB, D'Agostino Sr RB, et al. Trends in cardiovascular complications of diabetes. JAMA. 2004;292:2495-9.

3. Lind M, García Rodríguez LA, Booth GL, Cea Soriano L, Shah BR, Ekeroth $\mathrm{G}$, et al. Mortality trends in patients with and without diabetes in Ontario, Canada and the UK from 1996 to 2009: a population-based study. Diabetologia. 2013;56:2601-8.

4. New JP, Middleton RJ, Klebe B, Farmer CK, de Lusignan S, Stevens PE, et al. Assessing the prevalence, monitoring and management of chronic kidney disease in patients with diabetes compared with those without diabetes in general practice. Diabet Med. 2007;24:364-9.

5. Middleton RJ, Foley RN, Hegarty J, Cheung CM, McElduff P, Gibson JM, et al. The unrecognized prevalence of chronic kidney disease in diabetes. Nephrol Dial Transplant. 2006;21:88-92.

6. Ritz E, Rychlik I, Locatelli F, Halimi S. End-stage renal failure in type 2 diabetes: A medical catastrophe of worldwide dimensions. Am J Kidney Dis. 1999;34:795-808.

7. Hemmelgarn BR, Manns BJ, Lloyd A, James MT, Klarenbach S, Quinn RR, et al. Relation between kidney function, proteinuria, and adverse outcomes. JAMA. 2010;303:423-9.

8. Roderick PJ, Atkins RJ, Smeeth L, Mylne A, Nitsch DD, Hubbard RB, et al. CKD and mortality risk in older people: a community-based population study in the United Kingdom. Am J Kidney Dis. 2009;53:950-60.

9. Pizzarelli F, Lauretani F, Bandinelli S, Windham GB, Corsi AM, Giannelli SV, et al. Predictivity of survival according to different equations for estimating renal function in community-dwelling elderly subjects. Nephrol Dial Transplant. 2009;24:1197-205.

10. Weiner DE, Krassilnikova M, Tighiouart H, Salem DN, Levey AS, Sarnak MJ. CKD classification based on estimated GFR over three years and subsequent cardiac and mortality outcomes: a cohort study. BMC Nephrol. 2009;10:26.

11. Elley CR, Robinson E, Kenealy T, Bramley D, Drury PL. Derivation and validation of a new cardiovascular risk score for people with type 2 diabetes: the new zealand diabetes cohort study. Diabetes Care. 2010;33:1347-52.

12. Smith GL, Shlipak MG, Havranek EP, Foody JM, Masoudi FA, Rathore SS, et al. Serum urea nitrogen, creatinine, and estimators of renal function: mortality in older patients with cardiovascular disease. Arch Intern Med. 2006;166:1134-42.

13. Schou M, Torp-Pedersen C, Gustafsson F, Abdulla J, Kober L. Wall motion index, estimated glomerular filtration rate and mortality risk in patients with heart failure or myocardial infarction: a pooled analysis of 18,010 patients. Eur J Heart Fail. 2008;10:682-8.

14. Hillege HL, Nitsch D, Pfeffer MA, Swedberg K, McMurray JJ, Yusuf S, et al. Renal function as a predictor of outcome in a broad spectrum of patients with heart failure. Circulation. 2006;113:671-8.

15. Lin Y, Zheng Z, Li Y, Yuan $X$, Hou J, Zhang S, et al. Impact of renal dysfunction on long-term survival after isolated coronary artery bypass surgery. Ann Thorac Surg. 2009;87:1079-84.

16. Brown JR, Cochran RP, Mackenzie TA, Furnary AP, Kunzelman KS, Ross CS, et al. Long-term survival after cardiac surgery is predicted by estimated glomerular filtration rate. Ann Thorac Surg. 2008;86:4-11.

17. Conway B, Webster A, Ramsay G, Morgan N, Neary J, Whitworth C, et al. Predicting mortality and uptake of renal replacement therapy in patients with stage 4 chronic kidney disease. Nephrol Dial Transplant. 2009;24:1930-7.

18. He X, Moore J, Shabir S, Little MA, Cockwell P, Ball S, et al. Comparison of the predictive performance of eGFR formulae for mortality and graft failure in renal transplant recipients. Transplantation. 2009:87:384-92.

19. Lin CC, Chen CC, Kung PT, Li Cl, Yang SY, Liu CS, et al. Joint relationship between renal function and proteinuria on mortality of patients with type 2 diabetes: the Taichung Diabetes Study. Cardiovasc Diabetol. 2012;11:131.

20. Fox CS, Matsushita K, Woodward M, Bilo HJ, Chalmers J, Heerspink HJ, et al. Associations of kidney disease measures with mortality and end-stage renal disease in individuals with and without diabetes: a meta-analysis. Lancet. 2012;380:1662-73.

21. Berhane AM, Weil EJ, Knowler WC, Nelson RG, Hanson RL. Albuminuria and estimated glomerular filtration rate as predictors of diabetic end-stage renal disease and death. Clin J Am Soc Nephrol. 2011;6:2444-51.

22. So WY, Kong AP, Ma RC, Ozaki R, Szeto CC, Chan NN, et al. Glomerular filtration rate, cardiorenal end points, and all-cause mortality in type 2 diabetic patients. Diabetes Care. 2006;29:2046-52.
23. Bruno G, Merletti F, Bargero G, Novelli G, Melis D, Soddu A, et al. Estimated glomerular filtration rate, albuminuria and mortality in type 2 diabetes: the Casale Monferrato study. Diabetologia. 2007;50:941-8.

24. Nag S, Bilous R, Kelly W, Jones S, Roper N, Connolly V. All-cause and cardiovascular mortality in diabetic subjects increases significantly with reduced estimated glomerular filtration rate (eGFR): 10 years' data from the South Tees Diabetes Mortality study. Diabet Med. 2007;24:10-7.

25. Svensson MK, Cederholm J, Eliasson B, Zethelius B, Gudbjornsdottir S. Albuminuria and renal function as predictors of cardiovascular events and mortality in a general population of patients with type 2 diabetes: a nationwide observational study from the Swedish National Diabetes Register. Diab Vasc Dis Res. 2013;10:520-9.

26. Tsai CW, Grams ME, Inker LA, Coresh J, Selvin E. Cystatin C- and creatinine-based estimated glomerular filtration rate, vascular disease, and mortality in persons with diabetes in the U.S. Diabetes Care. 2014;37:1002-8.

27. Penno G, Solini A, Zoppini G, Orsi E, Fondelli C, Zerbini G, et al. Hemoglobin A1c variability as an independent correlate of cardiovascular disease in patients with type 2 diabetes: a cross-sectional analysis of the renal insufficiency and cardiovascular events (RIACE) Italian multicenter study. Cardiovasc Diabetol. 2013;12:98.

28. Drury PL, Ting R, Zannino D, Ehnholm C, Flack J, Whiting M, et al. Estimated glomerular filtration rate and albuminuria are independent predictors of cardiovascular events and death in type 2 diabetes mellitus: the Fenofibrate Intervention and Event Lowering in Diabetes (FIELD) study. Diabetologia. 2011;54:32-43.

29. Bourke A, Dattani H, Robinson M. Feasibility study and methodology to create a quality-evaluated database of primary care data. Inform Prim Care. 2004;12:171-7.

30. Lewis JD, Schinnar R, Bilker WB, Wang X, Strom BL. Validation studies of The Health Improvement Network (THIN) database for pharmacoepidemiology research. Pharmacoepidemiol Drug Saf. 2007;16:393-401.

31. Denburg MR, Haynes K, Shults J, Lewis JD, Leonard MB. Validation of The Health Improvement Network (THIN) database for epidemiologic studies of chronic kidney disease. Pharmacoepidemiol Drug Saf. 2011;20:1138-49.

32. Stuart-Buttle CD, Read JD, Sanderson HF, Sutton YM. A language of health in action: Read codes, classifications and groupings. Proc AMIA Annu Fall Symp. 1996:75-79.

33. Multilex for primary care. [http://www.fdbhealth.co.uk/multilex-overview/]

34. González EL, Johansson S, Wallander MA, García Rodríguez LA. Trends in the prevalence and incidence of diabetes in the UK: 1996-2005. J Epidemiol Community Health. 2009;63:332-6.

35. Rodriguez G, Soriano LC, Choi HK. Impact of diabetes against the future risk of developing gout. Ann Rheum Dis. 2010;69:2090-4.

36. García Rodríguez LA, Tacconelli S, Patrignani P. Role of dose potency in the prediction of risk of myocardial infarction associated with nonsteroidal anti-inflammatory drugs in the general population. J Am Coll Cardiol. 2008:52:1628-36.

37. Ruigomez A, Martin-Merino E, García Rodríguez LA. Validation of ischemic cerebrovascular diagnoses in the health improvement network (THIN). Pharmacoepidemiol Drug Saf. 2010;19:579-85.

38. García Rodríguez LA, Cea Soriano L, Hill C, Johansson S. Increased risk of stroke after discontinuation of acetylsalicylic acid: a UK primary care study. Neurology. 2011;76:740-6.

39. Townsend P, Phillimore P, Beattie A. Health and Deprivation: Inequality and the North. London: Croom Helm; 1988.

40. Shlipak MG, Fried LF, Crump C, Bleyer AJ, Manolio TA, Tracy RP, et al. Elevations of inflammatory and procoagulant biomarkers in elderly persons with renal insufficiency. Circulation. 2003;107:87-92.

41. Hsu CY, McCulloch CE, Curhan GC. Epidemiology of anemia associated with chronic renal insufficiency among adults in the United States: results from the Third National Health and Nutrition Examination Survey. J Am Soc Nephrol. 2002;13:504-10.

42. Blacher J, Safar ME, Guerin AP, Pannier B, Marchais SJ, London GM. Aortic pulse wave velocity index and mortality in end-stage renal disease. Kidney Int. 2003;63:1852-60.

43. Natarajan A, Marshall SM, Kesteven PJ, McComb JM, Rutter MK. Impact of biomarkers for endothelial dysfunction and procoagulant state on 10-year cardiovascular risk in Type 2 diabetes. Diabet Med. 2011;28:1201-5. 
44. Thomas MC, Maclsaac RJ, Tsalamandris C, Power D, Jerums G. Unrecognized anemia in patients with diabetes: a cross-sectional survey. Diabetes Care. 2003:26:1164-9.

45. De Vriese AS, Verbeuren TJ, Van de Voorde J, Lameire NH, Vanhoutte PM. Endothelial dysfunction in diabetes. Br J Pharmacol. 2000;130:963-74.

46. Hsu PF, Sung SH, Cheng HM, Yeh JS, Liu WL, Chan WL, et al. Association of clinical symptomatic hypoglycemia with cardiovascular events and total mortality in type 2 diabetes: a nationwide population-based study. Diabetes Care. 2013;36:894-900

47. Huang ES, Laiteerapong N, Liu JY, John PM, Moffet HH, Karter AJ. Rates of complications and mortality in older patients with diabetes mellitus: the diabetes and aging study. JAMA Intern Med. 2014;174:251-8.

48. Stamler J, Vaccaro O, Neaton JD, Wentworth D. Diabetes, other risk factors, and 12-yr cardiovascular mortality for men screened in the Multiple Risk Factor Intervention Trial. Diabetes Care. 1993;16:434-44.

49. Turner RC, Millns H, Neil HA, Stratton IM, Manley SE, Matthews DR, et al. Risk factors for coronary artery disease in non-insulin dependent diabetes mellitus: United Kingdom Prospective Diabetes Study (UKPDS: 23). BMJ. 1998;316:823-8.

50. Carnethon MR, Rasmussen-Torvik LJ, Palaniappan L. The obesity paradox in diabetes. Curr Cardiol Rep. 2014;16:446.

51. The management of type 2 diabetes (CG87). [http://www.nice.org.uk/ guidance/cg87/resources/guidance-type-2-diabetes-pdf]

52. Danaei G, García Rodríguez LA, Fernandez Cantero O, Hernan MA. Statins and risk of diabetes: an analysis of electronic medical records to evaluate possible bias due to differential survival. Diabetes Care. 2013;36:1236-40.

53. Martin-Merino E, Fortuny J, Rivero E, García Rodríguez LA. Validation of diabetic retinopathy and maculopathy diagnoses recorded in a U.K. primary care database. Diabetes Care. 2012;35:762-7.

54. Huerta C, Zhao SZ, García Rodríguez LA. Risk of acute liver injury in patients with diabetes. Pharmacotherapy. 2002;22:1091-6.

55. Pugliese G, Solini A, Bonora E, Orsi E, Zerbini G, Fondelli C, et al. Distribution of cardiovascular disease and retinopathy in patients with type 2 diabetes according to different classification systems for chronic kidney disease: a cross-sectional analysis of the renal insufficiency and cardiovascular events (RIACE) Italian multicenter study. Cardiovasc Diabetol. 2014;13:59.

56. Yokoyama H, Araki S, Haneda M, Matsushima M, Kawai K, Hirao K, et al. Chronic kidney disease categories and renal-cardiovascular outcomes in type 2 diabetes without prevalent cardiovascular disease: a prospective cohort study (JDDM25). Diabetologia. 2012;55:1911-8.

57. Chronic kidney disease: early identification and management of chronic kidney disease in adults in primary and secondary care (CG182). [http://www.nice.org.uk guidance/cg182/resources/guidance-chronic-kidney-disease-pdf]

58. Poggio ED, Wang X, Greene T, Van Lente F, Hall PM. Performance of the modification of diet in renal disease and Cockcroft-Gault equations in the estimation of GFR in health and in chronic kidney disease. J Am Soc Nephrol. 2005;16:459-66.

\section{Submit your next manuscript to BioMed Central and take full advantage of:}

- Convenient online submission

- Thorough peer review

- No space constraints or color figure charges

- Immediate publication on acceptance

- Inclusion in PubMed, CAS, Scopus and Google Scholar

- Research which is freely available for redistribution

Submit your manuscript at www.biomedcentral.com/submit 